\title{
The Use of Vietnamese In Learning English As A Second Language
}

Vinh Phu Tran ${ }^{1}$ and Nhon Dang ${ }^{1, *}$

${ }^{1}$ School of Humanities and Languages, Tan Tao University, Duc Hoa, Long An, 850000, Viet Nam.

ABSTRACT These years, the debate surrounding the role of the first language (L1) in the second/foreign language (L2) classrooms in general and in English ones has been a controversial issue. On one hand, people support the idea that the influence of mother tongue should be excluded from second language acquisition. Meanwhile, the component of English-only method emphasizes the significance from the use of $L 1$ in English classes. This paper aims to investigate the positive influences of the use of Vietnamese in English learning process. From this point, two main things will be demonstrated. Firstly, using Vietnamese has a facilitating role to play in the classroom and can actually boost students' learning. And secondly, there are good reasons for teachers and students to use Vietnamese to fully suit the context of specific lessons. To conduct this study, both quantitative and qualitative approaches were used. First of all, an online survey was conducted to collect realistic information from the students' perspective. On the other hand, there were some in-depth interviews for teachers and tutors to express their experience as well as their own ideas about this issue. Finally, two separate classes were formally observed when they took a sample lesson which was taught in different methods. At the end of the course, a small test was provided to students to examine how much they understood their lesson. All the statistics and information received was analyzed, then mentioned in the paper.

DOI: https://doi.org/10.53901/xndj7au548u
KEYWORDS

Positive influence

Vietnamese

Facilitate

English acquisition

Quantitative

Qualitative

ARTICLE HISTORY

Received: 15.07.2020

Accepted: 01.08.2020

Online: 10.08.2020

\section{INTRODUCTION}

Vietnam is in the "golden population period" with a high number of people in working-age; however, the quality of our labor force is not "golden". In the interview with Vietnamnet Bridge [1], Mr. Nguyen Van Thuat from the National center for Socio-economic information and forecast (NCIF) stated that more than 43 million Vietnamese people (about 79.1 percent) in the labor force do not have enough technical qualifications, especially on English communication skills. Because of their poor English listening and speaking skills, a large number of fresh university graduates have not been employed.

Being a market language, English itself becomes a global phenomena for everyone to integrate successfully into the world community and at the same time into the world market. Inextricably intertwined, there are controversial concerns to find appropriate methods to facilitate the learning process. While some people support the L2 only method; others emphasize the significant influences of the use of L1 on L2 acquisition. The paper aims to examine the positive side of bilingual methods using Vietnamese in teaching and learning English to finally answer the question: When and how much should Vietnamese be used in English classes?

\section{LITERATURE REVIEW}

Grammar Translation method (GTM) versus Communicative Approach (CA)

It's undeniable that the GTM and CA both have considerable influences on teaching and learning processes in general, and in grammar acquisition in particular. Chang [2] conducted a contrastive study of GTM and CA in teaching English grammar in Taiwan, to compare the pros and cons of these two approaches. 86 
students from the Taiwan Applied Foreign Language Department participated in the study. Finally, he found that in accuracy purposes, the Grammar Translation Method is much more effective than the CA; but the latter is better than in fluency aspects. From that point, he concluded that the ideal approach can be produced by emerging the two methods in teaching.

\section{Monolingual method support}

From the monolingual supporters point of view, the method is effective owing three fundamental principles. They argue that human beings are exposed to the surrounding sound environment. We listen, imitate and respond to what we hear around us and then we succeed in mastering our L1. And the same thing happens to the L2 learning process. Brown [3] mentioned that if we are put into an environment fully using L2, it's more likely for us to be successful in acquiring this language.

Secondly, the interference of L1 is a source of errors in learners' L2 performance. Research showed that "a high amount of first language influence" is found in "situations where translation exercises are frequent" [4]. Moreover, it may also leave the students with a sense of frustration when they experience realistic situations where they have to use L2 to communicate.

Finally, not only can the use of only L2 for all interactions in the L2 classroom proclaim the significance of L2 in satisfying the learners, but it also gets rid of making language learning experience uninspiring and boring. Students will find themselves to be motivated, which boosts their performance very much.

\section{Bilingual approach support}

According to Yadav [5], mother tongue creates significant influences on a child's life. Not only is mother tongue a part of one's personal, social and cultural identity, but it enforces the successful social patterns of their acting and speaking. In addition, mother tongue, in some aspects, positively affects children's education as well. Yadav stated that mother tongue-based education, especially benefits disadvantaged groups, including children from rural communities and girls, who tend to have less exposure to an official language

There is another strong evidence from the perspective of students that when learning a foreign language, students tend to prefer teachers who understand their L1. To be specific, a study by Schweers found that $88.7 \%$ of Spanish students studying English wanted L1 used in the class because it facilitates learning. Students also desired up to $39 \%$ of class time be spent in L1 [6].

On the other hand, Nguyen and Bui [7] pointed out a couple of main reasons for using Vietnamese in communicative English classes. The very first reason is that bilingualism is widely regarded as the easiest measure for students to get the teacher's guidance. Put another way, both Vietnamese teachers and students find that there's a need for them to use Vietnamese in classes to ensure the lessons can be fully distributed in an easy way so that students can understand without ambiguity. Secondly, for those who just get used to studying English, translation, therefore, may help a great deal because it generally consumes less time as well as more effective than using complete English explanation.

\section{METHODOLOGY}

As mentioned above, to achieve the final purpose of this study, three different approaches were used for data collection in an objectively and formally process. Specifically, an online survey, four in-depth interviews and a detailed observation were conducted.

\section{Online survey}

An online questionnaire on Google Form (go to Appendix A for more details) was sent to students from 5 schools: Tan Tao University and Tan Tao Talented School for The Gifted which both located in Duc Hoa District, Long An Province; Le Minh Xuan High School located in Binh Chanh District, Ho Chi Minh City; Tan Cong Sinh Junior High School in Tan Cong Sinh Village, Tam Nong District, Dong Thap Province; and Phu Cuong C Primary School in Phu Cuong Village, Tam Nong District, Dong Thap Province. Finally, there were 60 participants whose levels are from grade 4th to college students. In general, high school students accounted for most of the participants, about $47 \%$. They were asked to finish the questionnaire including 16 multiple choice questions about their experience and perspective on the use of Vietnamese in their English classes.

\section{Interviews}

To collect objective data from teachers' perspective, 4 semiinterviews were organized. Among 4 teachers. 3 of them already had a MA degree on English Teaching. They aged between 25 and 51; their teaching experience ranged from 3 to 17 years. Specifically, 4 interviewed teachers were: Mr. Nguyen Huy Hoang from Phu Cuong C Primary School, Mrs. Vo Thi Thuy Lieu from Tan Cong Sinh Junior High School, Mrs. Nguyen Thi My Ngan and Mrs. Le Thi Diem Mi are both from Tan Tao Talented School for The Gifted. A list of key questions (see Appendix B) were given to elicit the teachers' attitude as well as their experience on the use of L1 in general, and Vietnamese in particular when teaching English. Each interview lasted for about 15-20 minutes. Because of physical location differences, Mr. Hoang and Mrs. Lieu were interviewed through Messenger Video chat, while Mrs. Ngan and Mrs. Mi experienced face to face meetings.

\section{Experiment}

For qualitative figures, I had two separate classes at Anh - My Hoa English Center, which is located in Hau Nghia Village, Duc Hoa District, Long An Province, to participate in my experiment. The number of students in each class was 15 , and all of the students were at starter level (from grade 6th to grade 7 th). In other words, their levels were more or less the same. The process of my experiment involved 3 steps. First of all, the students were asked to finish a pretest to examine their current levels. Then, they spent 2 weeks (3 periods per week) studying a sample lesson about two grammatical points: simple past and present perfect tense. However, two different methods were applied. While in one class, only English was allowed; in the others, teachers and students could use Vietnamese for translation. To ensure the quality of experiment components, I suddenly came to those classes for formal observation twice. After finishing the sample curriculum, both classes did the same posttest for checking their overall understanding.

\section{RESULTS AND DISCUSSION}

As Table. 1 from the online survey among 60 students, $83 \%$ of them used to study in classes using 100\% English. However, their satisfaction about those classes was not so positive. Specifically, on the scale of 5 levels, 28 students' score was lower than 3 , which accounted for nearly $47 \%$.

On the other hand, when being asked about their experience on Vietnamese-used classes, more than $86 \%$ of students affirm that their teachers did use Vietnamese in English lessons. And, more than $58 \%$ of students said that the translation method helps them feel more comfortable with learning English. They provided 
Table 1 Satisfaction levels of students on English-only classes

\begin{tabular}{l|c|r} 
Levels of satisfaction & Number of students & Percentage \\
\hline 1 & 8 & 13.3 \\
2 & 20 & 33.4 \\
3 & 14 & 23.3 \\
4 & 12 & 20 \\
5 & 6 & 10
\end{tabular}

3 main reasons which are the benefits of using reasonably Vietnamese, including: possible to avoid misunderstanding $(86,7 \%)$, easy for students to understand the lessons $(66,7 \%)$, through correspondences between 2 languages, students can have a deeper understanding $(55,6 \%)$. So obviously, from the perspective of students, Vietnamese can create a comfortable environment for students to study. This is one of the key factors leading to further qualified performance.

For the interview results, all of 4 teachers supported the idea that based on the level of students in a specific class, the teachers can decide whether they should use a monolingual or bilingual approach. Mrs. Ngan from TTS suggested that in the first period, teachers could ask their students to finish a small survey to test their levels. If they have no difficulty doing this survey, teachers will mostly use English and vice versa. In terms of using bilingual method, teachers can consider the ability of students to step by step reduce the amount of Vietnamese used in the classroom. When I asked them about which method they prefer, there were 2 opposite dimensions of answer. Both of the teachers from TTS to maximize the quantity of English used in the classroom, while Mr. Hoang and Mrs. Lieu were more likely to choose the bilingual method. It can be easy to explain, because the level of students they are teaching is completely different. TTS is a high school where students have basic knowledge of English. In other words, they can absorb a larger amount of language in comparison to lower grades. According to Mr. Hoang, primary students just get used to the use of Vietnamese. Suddenly switching to digest a large amount of a foreign language like English possibly makes them overwhelmed. One more point is because of the geographical condition. Tan Cong Sinh and Phu Cuong village are both in the rural area where students have a lot of limitations to access to effective ways and materials of learning English, which very much affects their level. Applying a curriculum fully using English may be beyond their capacity.

Finally is the experiment on 2 classes. As shown in the Table. 2, there was not a big gap between the learning capacity of 2 classes. In the pretest, the average score of the monolingual class (L2 class) was 7,53 (out of 15 points) in comparison with 7,33 points of the bilingual class (L1)

Table 2 Detailed points of the Pretest (out of 15 points)

\begin{tabular}{rrrrrrrrrrrrrrrrr}
\hline L1 & 6 & 5 & 6 & 6 & 7 & 9 & 11 & 9 & 8 & 8 & 8 & 5 & 6 & 10 & 6 & 7.33 \\
L2 & 7 & 7 & 8 & 4 & 5 & 5 & 6 & 6 & 12 & 8 & 9 & 10 & 10 & 9 & 7 & 7.53
\end{tabular}

After 2 weeks taking the sample curriculum, 2 classes were asked to finish another posttest about what they had learnt. From the Table. 3, it's undeniable that the monolingual class's students' performance was not as good as that of the bilingual one. Although the average points of both classes were improved, there was a considerable distance between the L1 and L2 class. While students from the L1 class got 10,67 points on average, students from the other class just got 8,8 (increasing by 1,27 points). Put another way, bilingual method shows the significance over the monolingual method in terms of teaching and learning English grammar.

Table 3 Detailed points of the Posttest (out of 15 points)

\begin{tabular}{rrrrrrrrrrrrrrrrr}
\hline L1 & 11 & 6 & 9 & 7 & 11 & 11 & 13 & 14 & 15 & 12 & 10 & 10 & 11 & 12 & 8 & 10.67 \\
L2 & 9 & 6 & 9 & 7 & 10 & 6 & 6 & 9 & 14 & 8 & 7 & 8 & 12 & 12 & 9 & 8.8 \\
\hline
\end{tabular}

\section{Situations and reasonable amount of Vietnamese used in En- glish classrooms}

The study clearly shows that the use of Vietnamese created positive influences on the processes of learning and teaching English. Not only does it simplify the learning process from which students' performance could be enhanced, but it also benefits teachers by effectively expressing the knowledge without language barriers. However, to maximize the effectiveness of English acquisition, Vietnamese should just be used in some specific situations with a suitable quantity. All 4 interviewed teachers completely agreed that in terms of teaching and learning English grammar, translation can be used to take advantage of the class time. The online survey displayed some situations when students desired to use Vietnamese. To be specific, along with grammar lessons, most of the students suggested that teachers should use L1 to explain vocabulary and to check for understanding after the lessons. They also suggested that $30 \%$ of the class time should be spent in Vietnamese. In other words, both Vietnamese and English should be reasonably used; however, Vietnamese should not be overused to guarantee that students can finally get the highest performance on their English skills.

\section{CONCLUSION}

Being in the debate surrounding the use of L1 on learning and teaching L2, this paper is expected to indicate the significance of Vietnamese on English acquisition. From the above advantages, my article highlights 2 main points. First of all, the bilingual method is an effective tool which should not be removed from English classes' activities, especially on grammar, vocabulary and checking for understanding. Secondly, Vietnamese should be used reasonably with a limited amount depending on the level of students and the context of the class. As a result, both teachers and learners can develop effective ways to adapt and finally achieve the best results they are looking for.

\section{REFERENCES}

[1] Labor quality is big problem for vietnam: reports. https:/ / english.vietnamnet.vn/fms/business/186863/laborquality-is-big-problem-for-vietnam-reports.html.

[2] Shih-Chuan Chang. A contrastive study of grammar translation method and communicative approach in teaching english grammar. English Language Teaching, 4, 062011. 
[3] H Brown. Principles of language learning and teaching : a course in second language acquisition. Pearson Education, White Plains, NY, 2014.

[4] Joel Walz. Second language acquisition and second language learning. stephen d. krashen oxford: Pergamon press, 1981. pp. 151. Studies in Second Language Acquisition, 5:134, 092008.

[5] Manoj Kumar Yadav. Role of mother tongue in second language learning. International Journal of Research, 1:572-582, 2014.

[6] C.W Schweers. Using 11 in the classroom. 1999.

[7] Nguyen Thi Tuyet Anh Dr. Bui Phu Hung. The use of vietnamese in english language classes - benefits and drawbacks. International Journal on Studies in English Language and Literature (IJSELL), Volume 2, Issue 12, December 2014, PP 24-26, 2014.

\section{APPENDIX A. SURVEY ON THE USE OF VIETNAMESE IN ENGLISH LEARNING PROCESS}

1. How long have you been learning English?
A. Less than 1 year
B. 1-3 years
C. 3-6 years
D. More than 6 years

2. How frequently do you use English?

$\begin{array}{lllllll}\text { Rarely } & 1 & 2 & 3 & 4 & 5 & \text { Very frequently }\end{array}$

3. In your K-12 classes, do your teachers use Vietnamese in teaching?
A. Yes
B. No
C. Maybe

4. Have you ever experienced a class using English only?
A. Yes
B. No
C. Maybe

5. Do you think the use of Vietnamese helps you understand English lessons more effectively?
A. Yes
B. No
C. Maybe

6. Do the translation method helps feel more comfortable with learning English?
A. Absolutely yes
B. Not really
C. Absolutely not

7. Do you think studying in English-only classes will boost your English learning process?
A. Yes
B. No

C. Maybe

8. Do you think students will depend too much on the use of Vietnamese instead of improving their own English skills?
A. Yes
B. No
C. Maybe

9. What do you think are the benefits of bilingual approach using both Vietnamese and English?

Easy for students to understand the lesson

Possible to avoid misunderstanding

The correspondence between two languages could be learned

Being overwhelmed due to large amount of vocabulary could be reduced

Other:

10. From your opinion, how many percent should Vietnamese be used in English classes?

A. It shouldn't be used at all

B. Less than $30 \%$

C. $30 \%-50 \%$

D. $50 \%-75 \%$

E. $75 \%-90 \%$

F. More than $90 \%$

G. Fully use Vietnamese

11. From your perspective, when and how much should Vietnamese be used in English classes?

- Explaining vocabulary

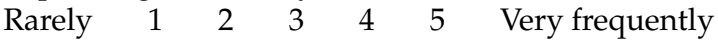

- Explaining grammatical points $\begin{array}{lllllll}\text { Rarely } & 1 & 2 & 3 & 4 & 5 & \text { Very frequently }\end{array}$

- Giving instructions for activities and tasks $\begin{array}{lllllll}\text { Rarely } & 1 & 2 & 3 & 4 & 5 & \text { Very frequently }\end{array}$

- Giving feedback after the lesson $\begin{array}{lllllll}\text { Rarely } & 1 & 2 & 3 & 4 & 5 & \text { Very frequently }\end{array}$

- Checking for understanding the lesson $\begin{array}{lllllll}\text { Rarely } & 1 & 2 & 3 & 4 & 5 & \text { Very frequently }\end{array}$ - Others - please specify

\section{APPENDIX B. INTERVIEW QUESTIONS SHEET}

Interviewee:
School:
Date:
Location:

Intended duration: Interview begin: Interview finished: Actual duration:

1. How long have you been teaching? 
2. In your classes, do you use the monolingual approach (English only) or the bilingual approach (both Vietnamese and English)?

3. Among these two methods, which one do you prefer?

4. Some people argue that L1 in general, or Vietnamese in particular should be excluded from English learning process. What do you think about it? (What do you think about using Vietnamese in teaching and learning English?)

5. From your perspective, should teachers use Vietnamese in teaching English?

6. If no, why should they not use Vietnamese?

7. If yes, in what situations should teachers use Vietnamese? (Prompts: explaining vocabulary, grammatical points, giving feedback,...)

8. How frequently should teachers use Vietnamese in English teaching? 